
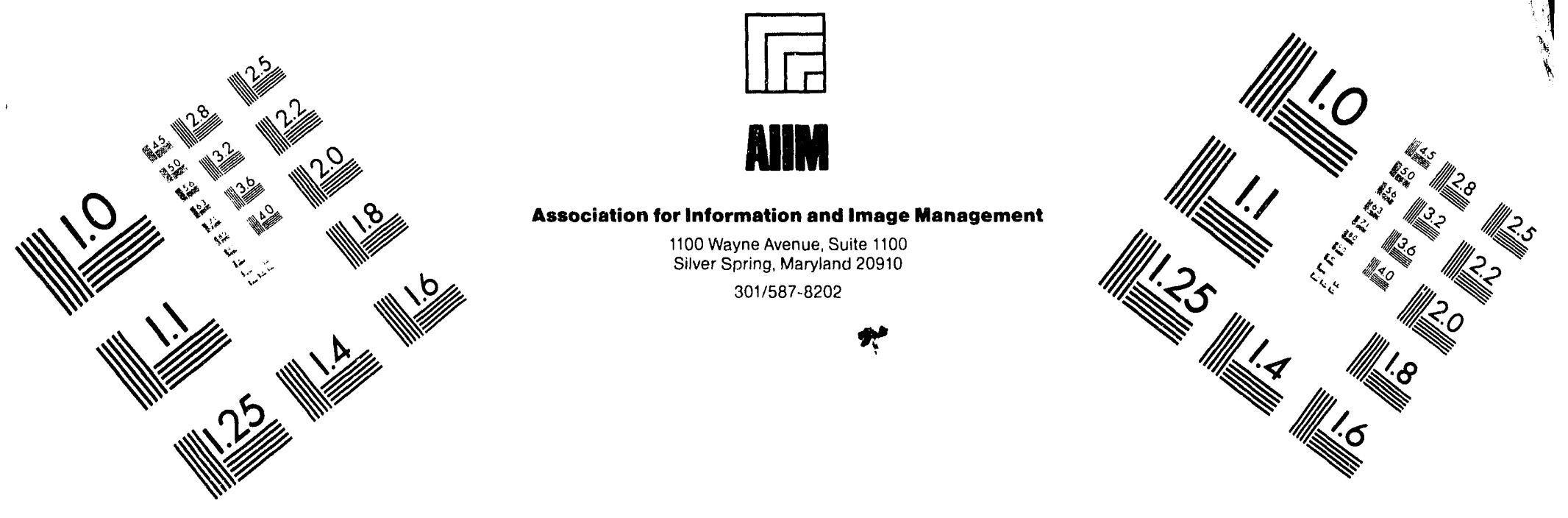

\title{
Centimeter
}

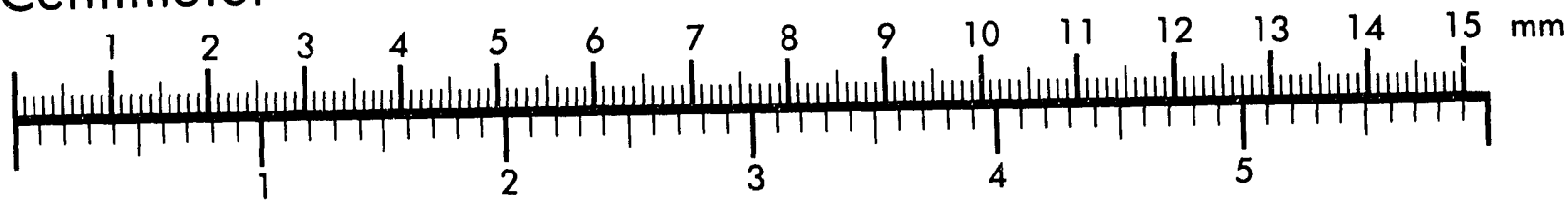
Inches
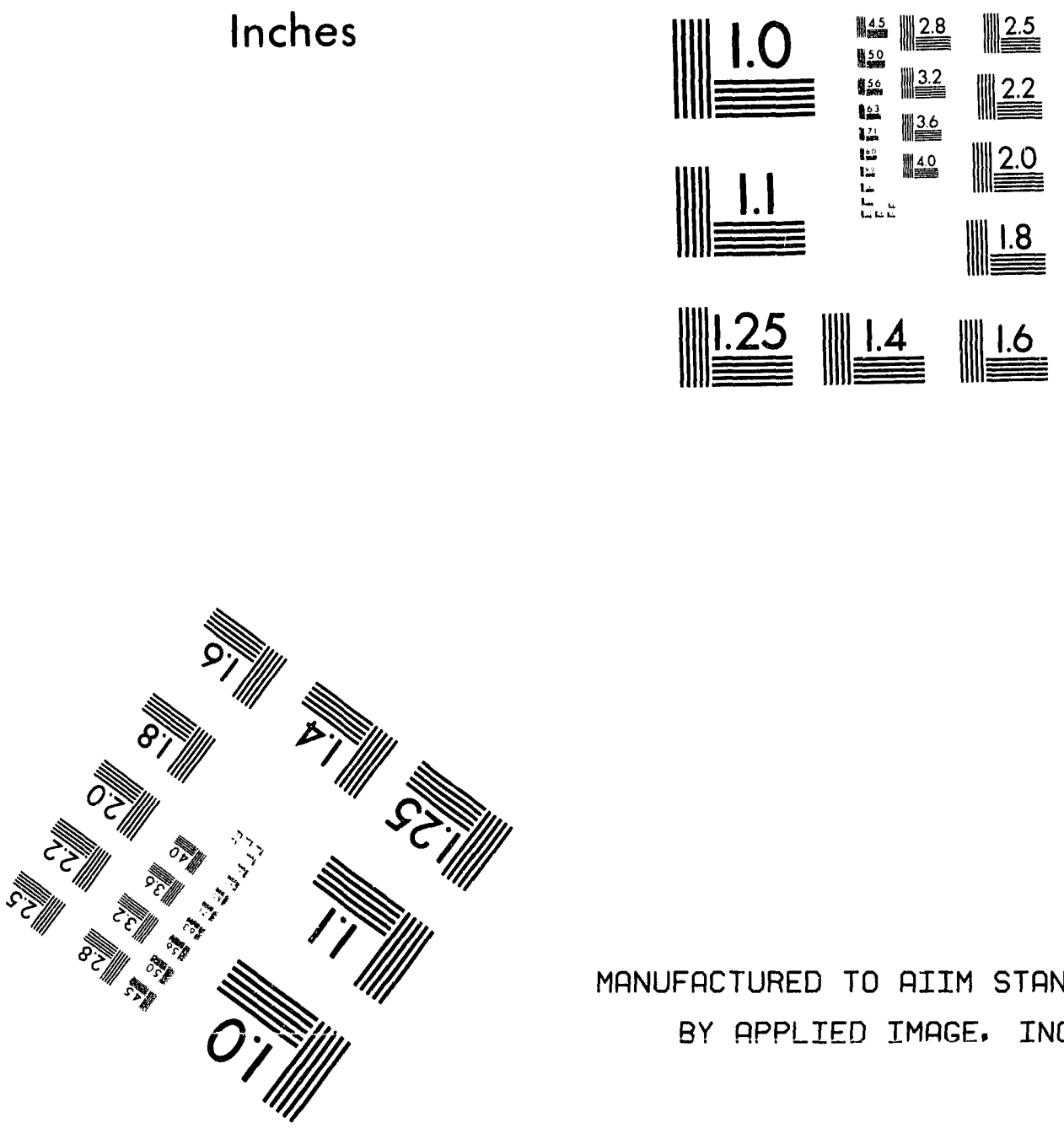

MANUFACTURED TO AIIM STANDARDS

BY APPLIED IMAGE. INC.

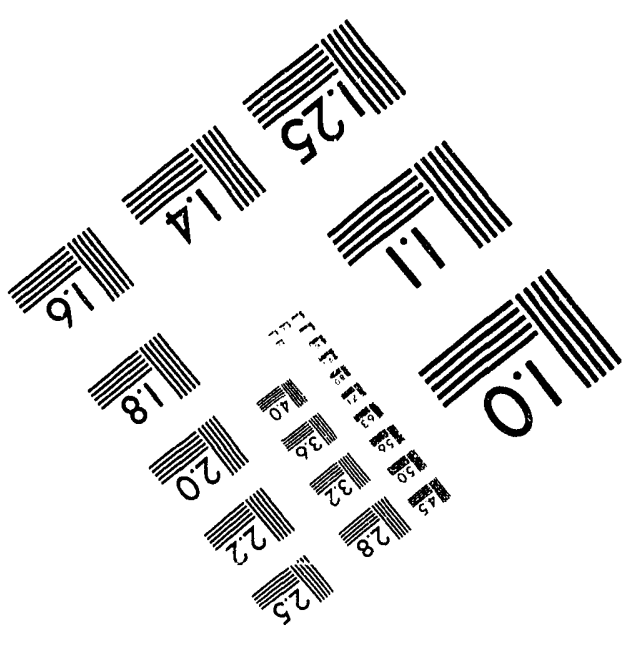



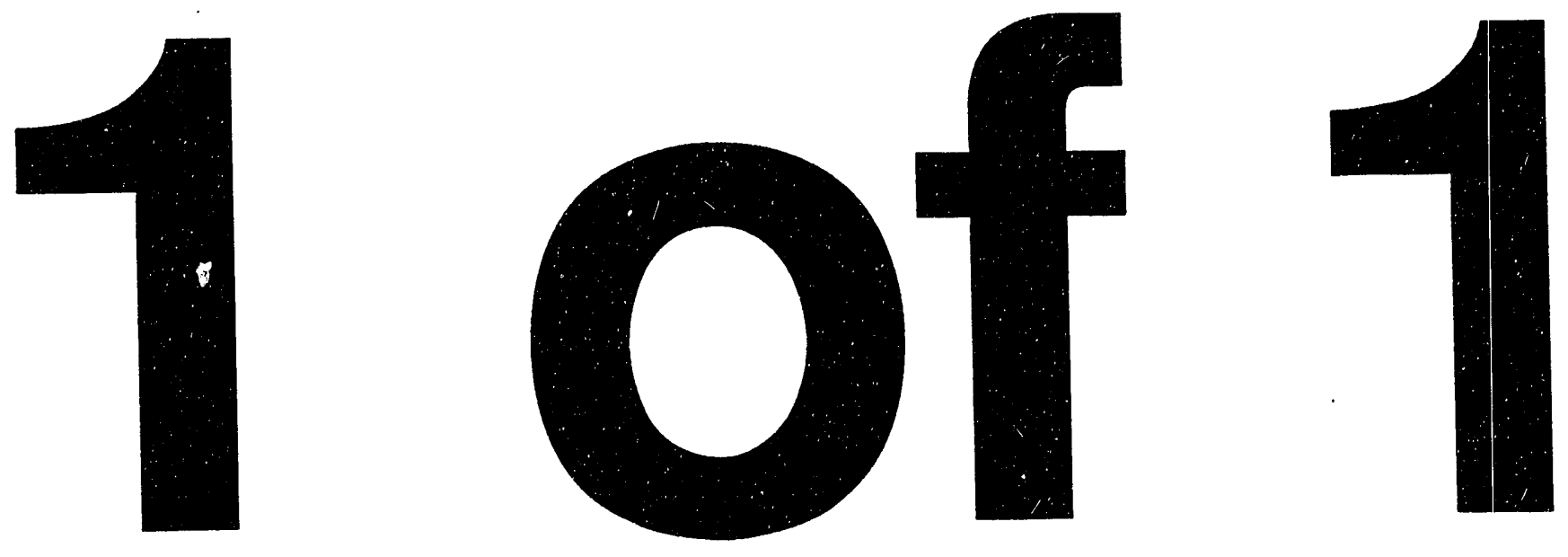


\section{HUMAN FACTORS EVALUATION OF LCS 254 AND 255 (U)}

by

L. Goffe

Westinghouse Savannah River Company

Savannah River Site

Aiken, South Carolina 29808

J. E. Held

WSRC

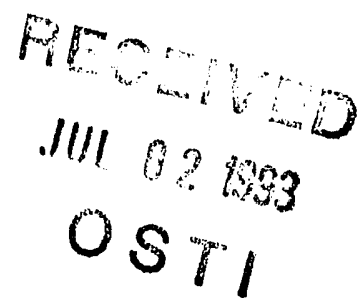

DOE Contract No. DE-AC09-89SR18035

This paper was prepared in connection with work done under the above contract number with the U. S. Department of Energy. By acceptance of this paper, the publisher and/or recipient acknowledges the U. S. Government's right to retain a nonexclusive, royalty-free license in and to any copyright covering this paper, along with the right to reproduce and to authorize others to reproduce all or part of the copyrighted paper. 


\section{UNCLASSIFIED}

NRT\&SC

Nuclear Reactor Technology and Scientific Computations
WSRC-TR-93-269

Rev. 0

Key Words Human Factors

Control Panel

Indicators

Design

Retention: Lifetime

\section{HUMAN FACTORS EVALUATION \\ OF LCS 254 AND 255 (U)}

by

\section{Goff \\ and}

J. E. IHeld

Issued: May 5, 1993

\section{WNOLASSIFIED}

Classification

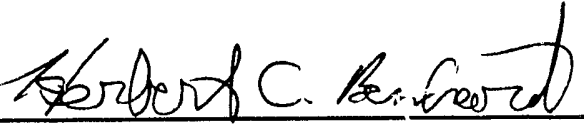

Derivative Classifier Reviewing Official

Westinghouse Savannah River Company

Savannah River Site

Aiken, SC 29808

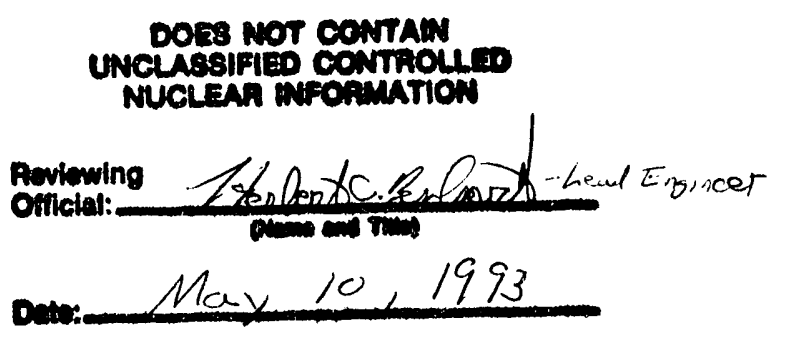

PREPARED FOR THE U. S. DEPARTMENT OF ENERGY UNDER CONTRACT NO. DE-AC09-8\$SR1803

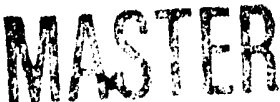


Document:

Title:
WSRC-TR-93-269

HUMAN FACTORS EVALUATION OF LCS

254 and 255 (U)

Approvals

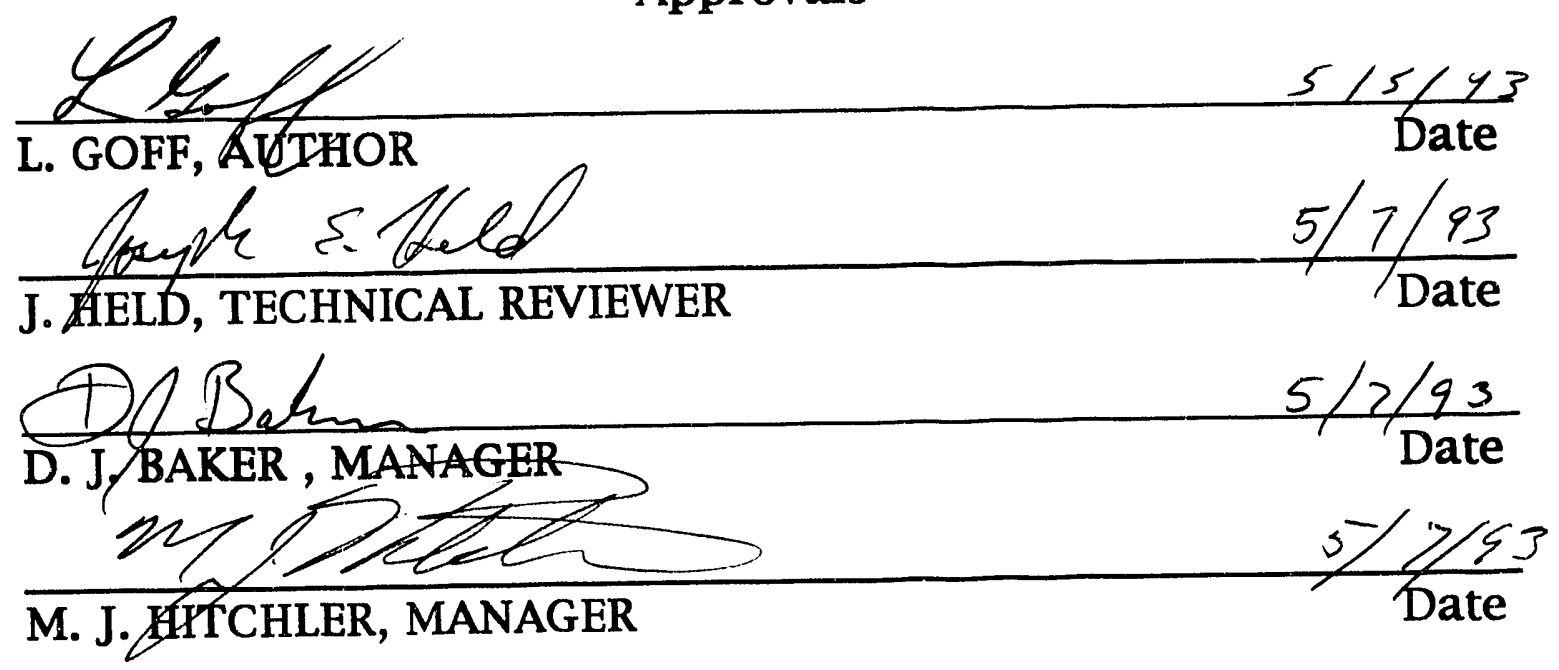




\section{DISCLAIMER}

This report was prepared as an account of work sponsored by an agency of the United States Government. Neither the United States Government nor any agency thereof, nor any of their employees, makes any warranty, express or implied, or assumes any legal liability or responsibility for the accuracy, completeness, or usefulness of any information, apparatus, product, or process disclosed, or represents that its use would not infringe privately owned rights. Reference herein to any specific commercial product, process or service by trade name, trademark, manufacturer, or otherwise does not necessarily constitute or imply endorsement, recommendation, or favoring by the United States Government or any agency thereof. The views and opinions of authors expressed herein do not necessarily state or reflect those of the United States Government or any agency thereof. 
WSRC-TR-93-269

Rev. 0

\section{TABLE OF CONTENTS}

\section{Page}

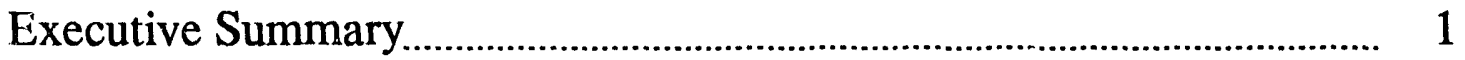

Introduction.

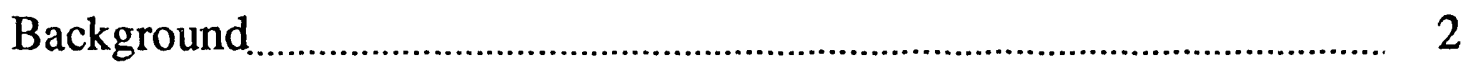

Review Findings

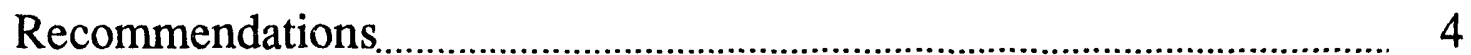

Summary

References

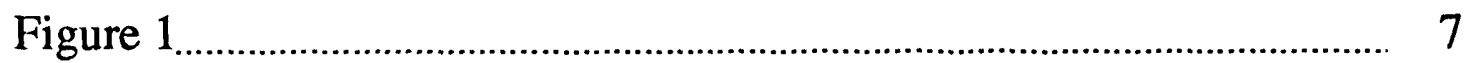

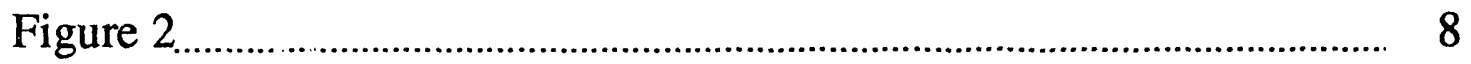

Figure 3

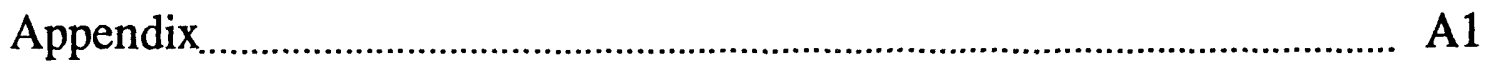




\section{HUMAN FACTORS EVALUATION OF LCS 254 AND 255 (U)}

\section{EXECUTIVE SUMMARY}

This report includes the results of the Human Factors evaluation of the local control stations (LCS) 254 and 255 performed by Savannah River Technology Center (SRTC) Human Factors. Recommendations are included in order that the panel designs will be upgraded to comply with human engineering design guidelines. Figures 1 and 2 are included as examples of recommended changes. Also, consideration was given to including the proposed engineering changes which are currently on-going for LCS 255 . Appendix A identifies the human engineering requirements from NUREG-0700 which were used in the evaluation process, and the areas of the design which do not comply with the guidelines. Those areas of the panel design which fail to comply with the human engineering guidelines are label location, label content, location aids, panel layout, and control display integration. Each of these design deficiencies and proposed corrections are described in this report. 


\section{HUMAN FACTORS EVALUATION OF LCS 254 AND 255 (U)}

\section{INTRODUCTION}

SRTC Human Factors Group reviewed LCS 254 and 255 panel because a walkdown review of the New Waste Transfer Facility (NWTF) building/pit ventilation system identified that the panel layouts of LCS 254 and 255 could mislead an operator. The panels were reviewed according to human engineering design guidelines. Recommendations are made for rearranging the controls, applying labels effectively and consistently, and for incorporating demarcation and coding techniques to support task performance and reduce operator error.

\section{BACKGROUND}

The NWTF provides for the transfer of radioactive slurries and solutions in the $200 \mathrm{H}$ area. It also serves as the receipt point for recycle waste transfers from Defense Waste Processing Facility (DWPF). The NWTF contains four pump pits (HPP7-10) and one diversion box (HDB8). The pump pits and diversion box are the lowest points in the pipeline systems they serve and are the drain points for all the lines except the DWPF recycle waste which drains to the Auxiliary Pump pit. LCS 254 in building 241-100H and 255 located outside building $241-101 \mathrm{H}$, provide control and monitoring capabilities for those areas (see Figure 3 ) which have a high potential for airborne contamination.

\section{REVIEW FINDINGS}

LCS 254 and 255 panel designs were reviewed for conformance with human engineering design guidelines as specified in NUREG-0700, "Guidelines for Control Room Design Reviews". The applicable detailed guidelines for reviewing the panels were used in the human engineering review (See Table 1, in Appendix A). Discrepancies are aspects of the panel design which do not comply with human engineering design guidelines described in NUREG-0700, "Guidelines for Control Room Design Reviews". The guidelines specify those design requirements for panel design which support operator performance and reduce operator error.

The following are human engineering discrepancies which do not comply with the labeling, panel design, and control-display integration requirements. The numbers in parenthesis after the headings below, are the relevant section numbers in NUREG-0700.

Labeling Principles (section 6.6.1.2)

A hierarchical labeling scheme helps reduce confusion, operator search time, and redundancy. A hierarchical labeling scheme is not prevalent in the current LCS 254 and 255 panel design.

NUREG-0700, section 6.6.1.2, states that a hierarchical scheme of ranking should be used for labeling control panels. "Major labels should be used to identify major systems or operator work stations. Subordinate labels should be used to identify subsystems or functional groups. Component labels should be used to identify each discrete panel or console element". Finally, "labels should not repeat information contained in higherlevel labels." Also, lettering size on labels should be graduated depending on hierarchical levels. System/work station labels are the largest. Subsystem/functional group labels are $25 \%$ larger than the component labels. The component labels should be $25 \%$ larger than the control position identifiers. 


\title{
HUMAN FACTORS EVALUATION OF LCS 254 AND 255 (U)
}

\author{
Label Location (section 6.6.2) \\ Labels are normally placed above the panel element(s) they describe. Proper placement \\ and consistency of label location will reduce search time and operator confusion. There \\ was a high degree of inconsistency of label location found in the panel design of LCS 254 \\ and 255. The majority of the labels for the switches/controls for LCS 254 and 255 were \\ located below the components rather than above.
}

Label Content (section 6.6.3)

Labels should be used to identify functionally grouped controls and displays. In the design of LCS 254 and 255 there is a lack of labeling for functionally grouped displays/controls. In LCS 254 , the lack of labeling for functionally grouped controls is due to poor placement of the controls in reference to the status indicators. In LCS 255, usage of functional gro:s labeling could greatly eliminate redundant terminology. Also, the labels should be placed above functionally related groups of components.

Use and Control of Temporary Labels (section 6.6.5)

Temporary labels should conform to good human engineering principles. Temporary labels should be located above the control rather than to the side. Temporary labels were located on the left side of some of the controls on LCS 254.

Location Aids (section 6.6.6)

Operator performance can be enhanced through the use of location aids such as demarcation, color, and mimics. Lines of demarcation can be used to distinguish related controls, helping personnel to recognize the meaning of groupings, and reduce operator search time. Color should be dedicated to specific functions or conditions in order to elicit the expected operator performance. On LCS 255, the status indicators (i.e. filter blown and filter) plugged are within the color coding guidelines described in section 6.5.1.6 of NUREG-0700.

Panel Layout (section 6.8.1)

Controls and displays should be arranged in functional groupings. This would promote easy understanding of the relationship between controls and system operation. On LCS 254 , it is not clear which inlet/outlet indicators belong to exhaust fan 1 and exhaust fan 2.

Effective Panel Layout (section 6.8.1.2)

The location of controls and displays within a single panel should make the most effective use of viewing and manual manipulative areas. Some of the controls on LCS 254 are not directly located below the associated displays.

Enhancing Recognition and Identification (section 6.8.1.3)

Several enhancement techniques are available for setting apart groups of controls and displays. Three preferred techniques are spacing, demarcation, and color shading. There is a lack of recognition and identification aids used on LCS 254 for setting apart functions of the different controls and status indicators.

Sequence, Frequency of Use, and Functional Considerations (section 6.8.2.1)

Controls and displays which are used together during a normal task sequence should be grouped together. The control switches on LCS 254 should be grouped in accordance to their functional indicators. 


\section{HUMAN FACTORS EVALUATION OF LCS 254 AND 255 (U)}

Logical Arrangement and Layout (section 6.8.2.2)

The arrangement of controls and displays should be logical, but should not compromise sequence of operations or functional integrity. On LCS 255, it would be logical to locate the status indicator filter blown above filter plug rather than visa-versa.

Control-Display Integration (section 6.9.1)

Related controls and displays should be easily identified as being associated. This association can be established (or enhanced) by (1) location, (2) labeling, (3) coding, (4) demarcation, and (5) consistency with operator expectations. The following relationships should be immediately apparent to the operator.

(1) Association of displays with controls

(2) The direction of movement of control and display.

(3) The rate and limits of movement of the control and display.

The layout of LCS 254 lacks demarcation and grouping of controls with their indicators to show association. Also a control switch should always provide feedback status to the operator. The damper control switch labeled HIS-8405 does not have a status indictor for feedback.

Location \& Arrangement of Control-Display Groups (section 6.9.2.1)

Multiple controls or displays related to the same function should be grouped together. The sequence of use should be as follows:

(1) Left to right

(2) Top to bottom

(3) The above combined

Some of the controls on LCS 254 were not located near their functionally related indicators.

General Movement Relationships (section 6.9.3.1)

Appropriate arrangements for control-display relationship, in order of preference, are (a) display above each control, (b) displays and controls in matched rows, and (c) multi-row displays with a single row of controls. Practice should be consistent, so that operator expectations are not confused. LCS 254 was not consistently laid out in reference to all displays or controls located on the same row.

\section{RECOMMENDATIONS}

The following is a list of recommendations to be made on the design of LCS 254 and 255. Not only will these changes ensure that LCS 254 and 255 comply with human engineering design guidelines, but they will also ensure that the design is not misleading to the operator (See Ref. 2).

\section{$\underline{\operatorname{LCS} 254}$}

\section{Preferred Action:}

Make use of demarcation lines to clarify functional realtionship of controls for:

(1) High/Bay Pump Pits Ventilation Indicators and Controls

(2) Filter Change Indicators

(3) Exhaust Fan 1

(4) Exhaust Fan 2 


\section{HUMAN FACTORS EVALUATION OF LCS 254 AND 255 (U)}

- Add an indicator light for HIS-8405. This will show consistency within the design with the usage of indicator lights for switch controls and provide feedback for the operator.

- All the labels should be located above the controls and displays. The name of the control or display should be located first, then additional information can follow which is used for troubleshooting and repair.

- The labeling for the BLDG/PIT VENTILATION FLOW INDICATING CONTROLLER and the BLDG/PIT VENTILATION MOISTURE INDICATING CONTROLLER should be placed above the controls. See Ref. 5 .

- $\quad$ Provide labeling for the outlet and inlet dampers.

- Arrange controls and displays into functional groupings. See Figure 1.

- $\quad$ Letter sizes should be changed to meet guidelines.

\section{LCS 255}

The alarm indicators should spell out the functions; such as, FILTER PLUGGED and BLOWN FILTER.

- Labels should be placed above their respective components. Make use of hierarchical levels .

Minimum Action:

LCS 254 - In response to the comments generated from the walkdown of the Building/Pit Ventilation system the above recommendations should be adhered to (See Ref. 3).

LCS 255 - The nomenclature on the alarm indicators should indicate: (1) filter plugged and (2) filter blown. 


\section{HUMAN FACTORS EVALUATION OF LCS 254 AND 255 (U)}

\section{SUMMARY}

LCS 254 and 255 panel drawings (see figure 1 and 2) represent Human Factors recommendations on the design modification effort of implementing human engineering design criteria. The controls and indicators on LCS 254 have been grouped according to functions. Also, human engineering criteria such as demarcation and labeling principles have been included in the design.

\section{REFERENCES}

1. NUREG-0700, Guidelines for Control Room Design Reviews

U. S. Nuclear regulatory Commission, Washington, D. C., September, 1981

2. Operation of HDB-8 Facility Pit/Building-Ventilation System (U) (Working Copy) 241-HDB8-1202.

3. O'Connor, J.L., "Walkdown of the Building/Pit Ventilation System" Inter-office Memo, 02/02/93.

4. $\quad$ SRT-STR-93-8003, New Waste Transfer Facility Panel, (LCS $254 \& 255$ ) Evaluation, (U), 3/17/93.

5. Y518-LCS-254, Drawing, \#W781103, 1-2-91.

6. Y518-LCS-255, Drawing, \#W781106, 1-2-91.

7. DOE 6430.1A, General Design Criteria, March 1989. 


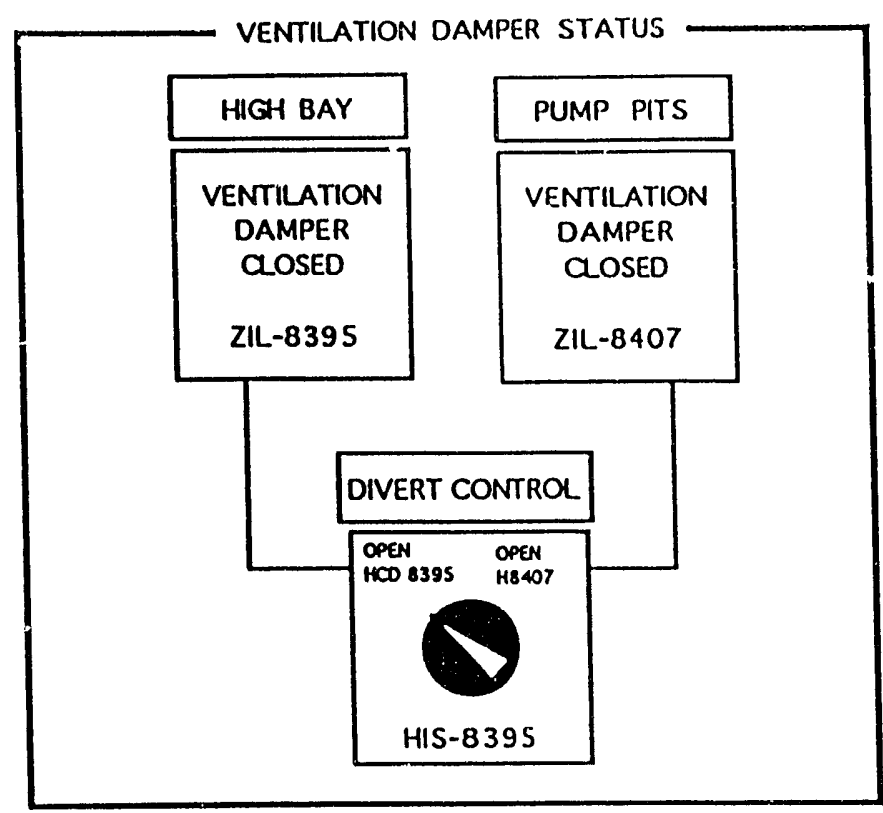

EXHAUST FAN 1

\begin{tabular}{|c|}
\hline INLET \\
\hline $\begin{array}{l}\text { ISOLATION } \\
\text { DAMPER } \\
\text { COOSED }\end{array}$ \\
\hline ZIL $-8402 A$ \\
\hline
\end{tabular}

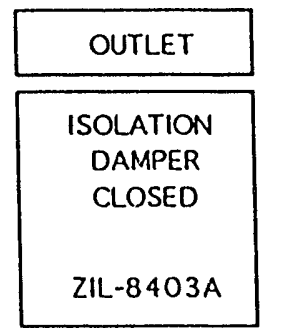

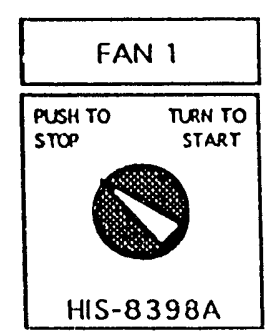

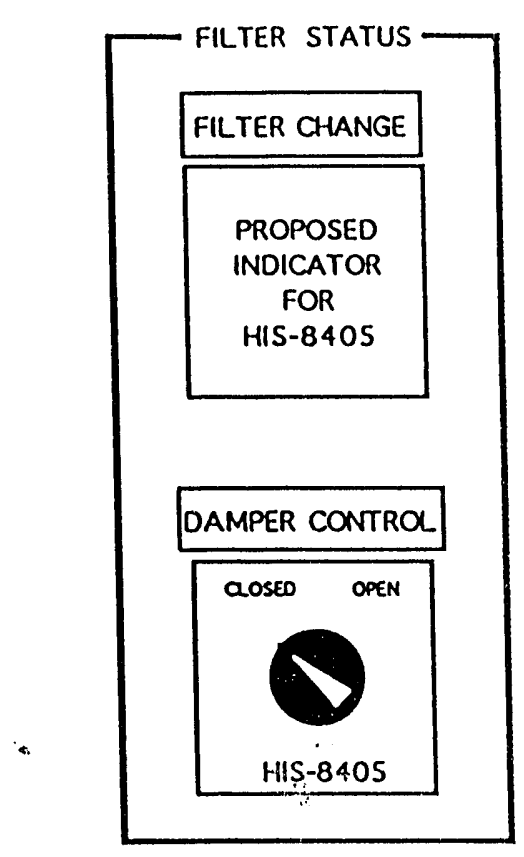

EXHAUST FAN 2
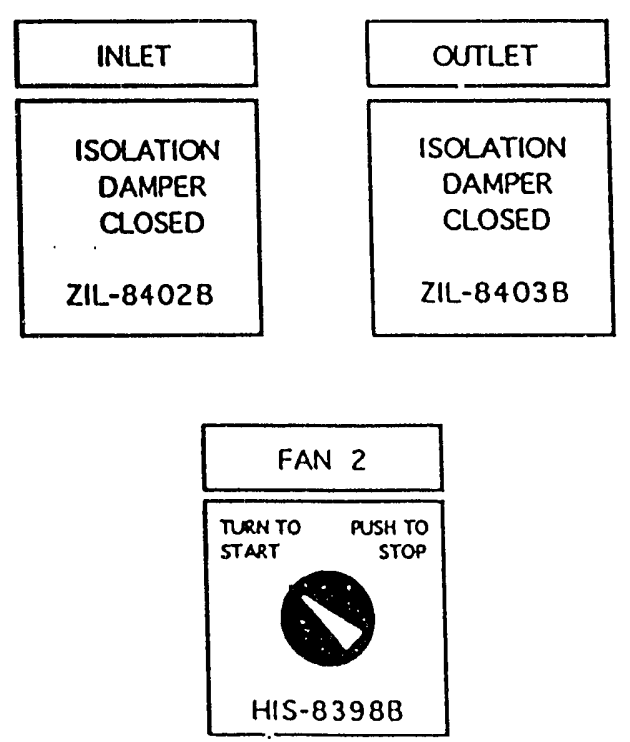


\section{HUMAN FACTORS EVALUATION OF LCS 254 AND 255 (U)}

\section{FIGURE 2. PANEL LCS-255 (U)}

Y518 LCS 255

HEPA FILTER HOUSING DIFF. PRESSURE (IN WATER)

\section{WEST HEPA FILTER SECTIONS}

-.- UPPER -...-

PDI-8399A

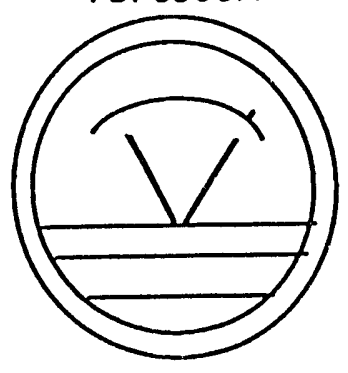

BLOWN

FILTER

PDAL-

8399A

FILTER

PLUGGED

PDOH-

8399A
-.-MIDDLE-...

PDI-8399B

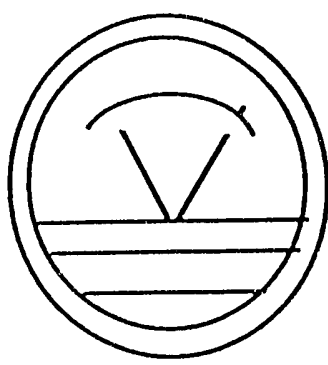

BLOWN

FILTER

PDAL-

8399B

FILTER

PLUGGED

PDOH-

8399B
-- LOWER-.-

PDI-8399C

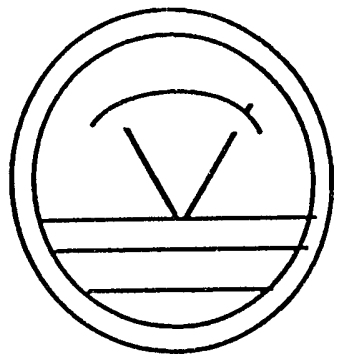

BLOWN

FILTER

PDAL-

8399C

FILTER

PLUGGED

$\mathrm{PDOH}-$

$8399 \mathrm{C}$

EAST HEPA FILTER SECTIONS

-.. UPPER -...-

PDI-8397A

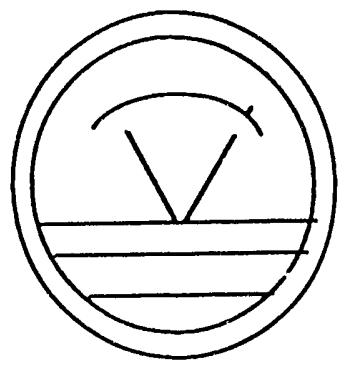

BLOWN

FILTER

PDAL-

8397A

FILTER

PLUGGED

$\mathrm{PDOH}$ -

8397A

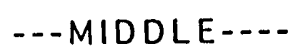

PDI-8397B

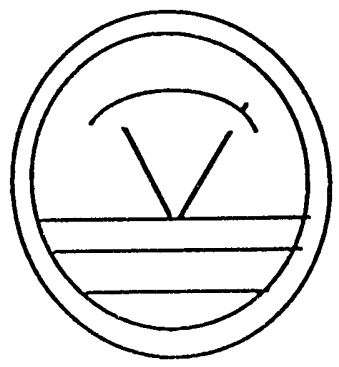

BLOWN

FILTER

PDAL-

8397B

FILTER

PLUGGED

$\mathrm{PDOH}-$

B397B
-- - LOWER---

PDI-8397C

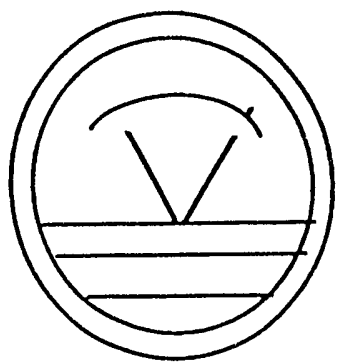

BLOWN

FILTER

PDAL-

8397C

FILTER

PLUGGED

PDOH-

$8397 \mathrm{C}$ 


\section{HUMAN FACTORS EVALUATION OF LCS 254 AND 255 (U)}

FIGURE 3. LOCATION OF INSTRUMENT PANELS LCS 254 AND 255 (U)

Human factors panel design

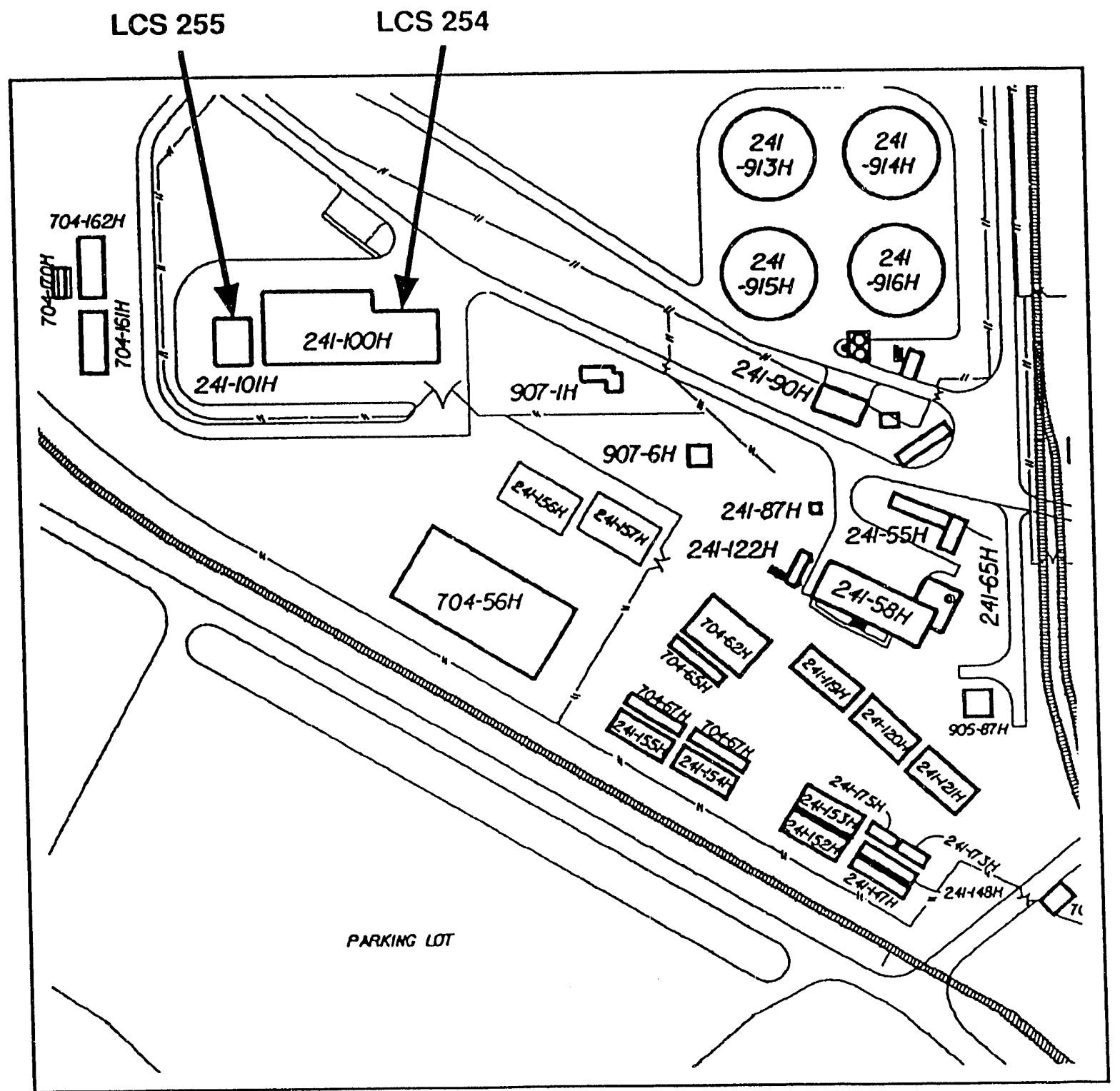




\section{APPENDIX}


TABLE 1

\subsection{LABELS AND LOCATION AIDS}

\subsubsection{LABELING PRINCIPLES}

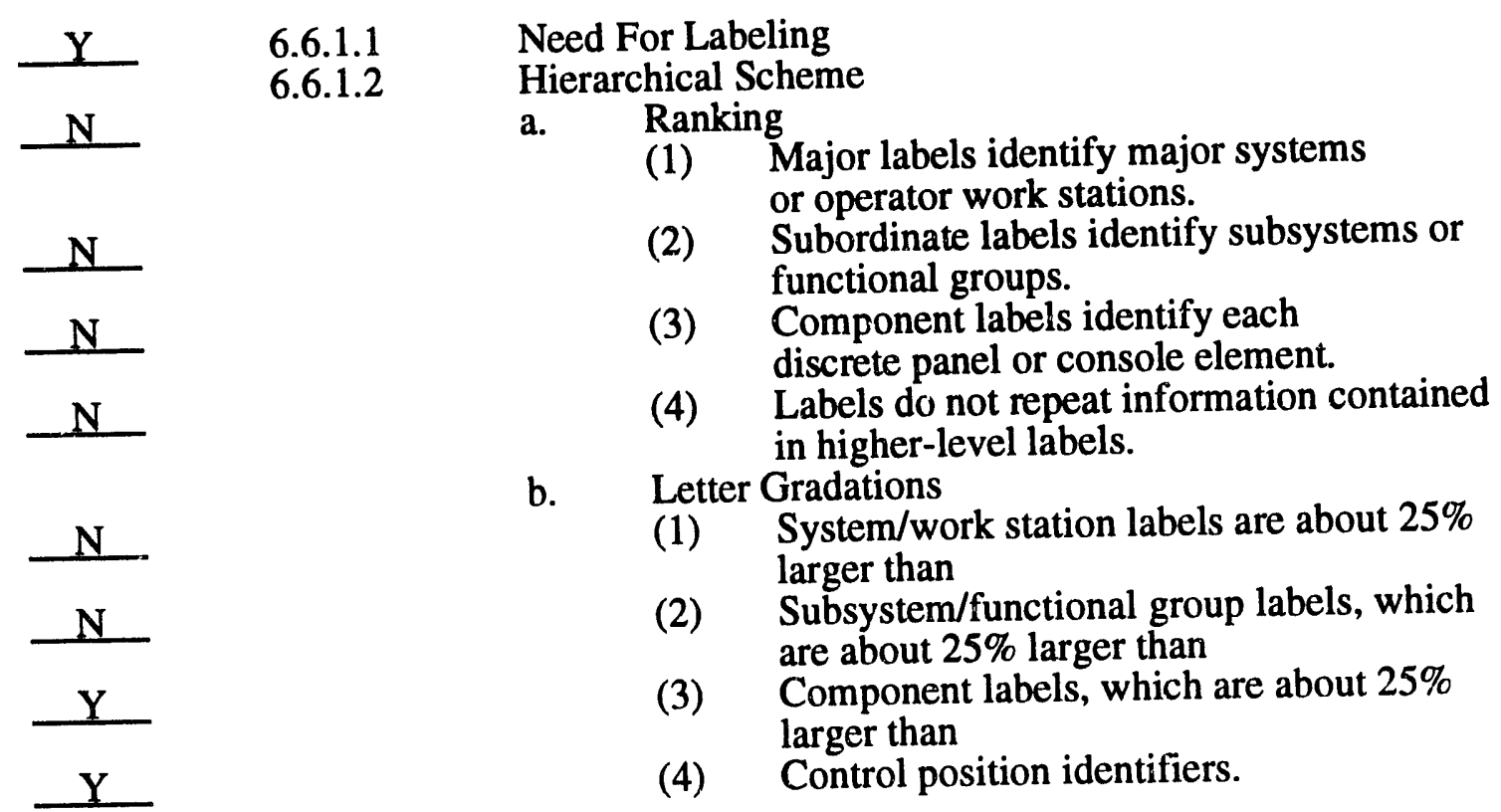

\subsubsection{LABEL LOCATION}

$\underline{N}$

6.6.2.1

$\frac{\frac{N}{N / A}}{\frac{Y}{Y}}$

$\mathrm{Y}$

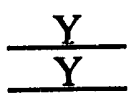

6.6.2.2

6.6.2.3

$\frac{Y}{N / A}$

N/A
Placement

a. Normal Placement (above the panel element)

b. Panel Labeling (Adhere to Exhibit 6.6-1)

c. Visibility Enhancement

d. Prciaimity

e. Labels on controls (should not be on the controls)

f. Adjacent labels (adequate separation)

Mounting

a. Integrity (preclude accidental removal)

b. Surface (flat)

Spatial Orientation

a. Horizontal Orientation

(1) Labels oriented horizontally

(2) Vertically oriented (if space is limited)

b. Curved Patterns (should be avoided)

N/A - Guideline is not applicable

Y - Yes, complies with guideline

$\mathrm{N}$ - No, does not comply with guideline 
6.6.2.4 Visibility

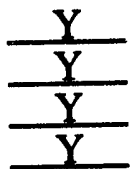
a. Other Information Sources
b. Concealment
c. Controls
d. Cleaning

\subsubsection{LABEL CONTENT}

6.6.3.1 Kinds of Information

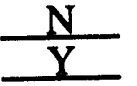
a. Primary Function
b. Secondary Function

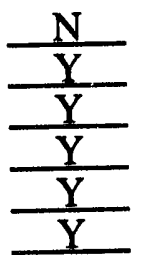

6.6.3.2

\section{Word Selection}
a. Intended Action
b. Clarity
c. Direct
d. Meaning
e. Technical Terms
f. Spelling

6.6.3.3 Consistency

$\frac{N}{N}$
a. Administrate Control
b. Internal Consistency
c. Consistency With Procedures

6.6.3.4 Symbols

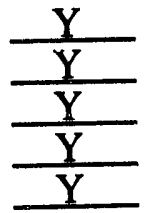
a. Meaning
b. Distinguishability
c. Standard
d. Consistency
e. Roman Numerals (not used)

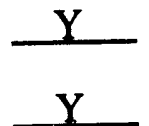

6.6.3.5

Brevity

6.6.3.6

Similarity

6.6.3.7

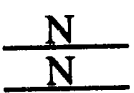

Functional Groups
a. Functional Relationship
b. Location

6.6.3.8

$\frac{\frac{N}{N / A}}{Y}$

Control Position Labeling
a. Position
b. Direction
c. Visibility

6.6.3.9 Access Opening, Danger, Warning, and Safety Instruction Labeling

$\frac{N / A}{Y}$

a. Access Opening Labels

b. Danger, Warning, and Safety Instruction Labels 


\subsubsection{LABEL LETTERING}

6.6.4.1 Readability

a. Character Height

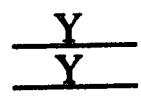

(1) Criteria

(2) Identical for all labels within the same hierarchical level.

b. CONTRAST

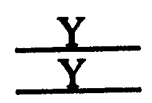
(1) Dark characters on a light background
(2) Use of color should conform to 6.5.1.6 (also see Exhibit 6.6-9).

6.6.4.2 Style (see Exhibits 6.5-1 and 6.5-2)
a. CHARACTER SELECTION

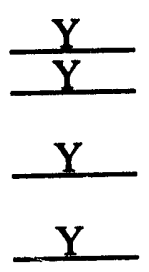

b. CHARACTER WIDTH

(1) Capital letters

(2) No flourishes or serifs.

(1) Letter width-to-height ratio, between $1: 1$ and 3:5.

(2) Numeral width-to-height ratio, 3:5 (except "4", which should be one stroke width wider, and "1", which should be one stroke in width).

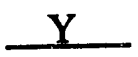

c. STROKE WIDTS - Stroke width-to-character height ratio should be between 1:6 and $1: 8$

d. SPACING

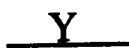

(1) Minimum between characters, one stroke width.

$\underline{Y}$

(2) Minimum between words, one character width.

$\mathrm{Y}$

(3) Minimum between lines, one-half of the character height.

\subsubsection{USE AND CONTROL OF TEMPORARY LABELS}

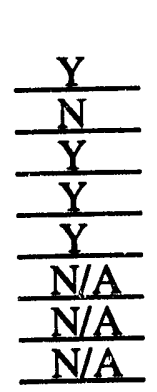

6.6.5.1

USE

a. NECESSITY

b. HUMAN FACTORS PRACTICES

c. VISIBILITY

d. IDENTIFICATION

e. MOUNTINS

f. OBSCURATION

g. ACTIVATION

h. ADJACENT DEVICES

6.6.5.2

\section{CONTROL}

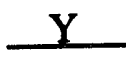

a. ADMINISTRATIVE PROCEDURES

b. REVIEW PROCEDURES

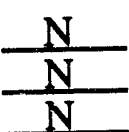

(1) When temporary labels are needed:

(2) How they will be used

(3) Their content (given human engineering requirements); 


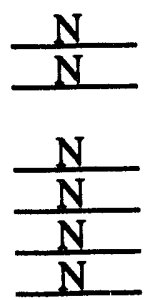

(4) their installation;

(5) the impact of their use on other system equipment;

(6) documentation requirements;

(7) re-training requirements;

(8) their periodic review; and

(9) their removal.

\subsubsection{LOCATION AIDS}

\section{$\mathrm{N} \quad 6.6 .6 .1$}

6.6.6.2

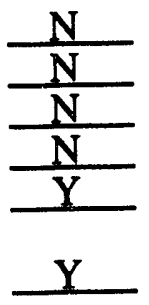

N/A

N/A

N/A

N/A

N/A

$\frac{\frac{N / A}{N / A}}{\frac{N / A}{N / A}} \frac{N / A}{N / A}$

N/A

\section{8}

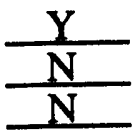

$\mathrm{N}$

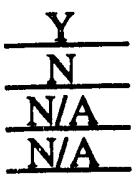

6.6.6.4

\section{NEED FOR LOCATION AIDS}

\section{DEMARCATION}

a. USE

(1) Enclose functionally related display.

(2) Enclose functionally related controls.

b. CONTRAST

(3) Group related controls and displays.

c. PERMANENCE

\subsubsection{COLOR}

USE OF MIMICS

a. COLOR

(1) Color coded flow paths (see 6.5.1.6).

(2) Colors are discriminably different.

(3) Contrast between panel and mimic.

(4) Consistent usage.

(5) Limit of 4 lines of same color in parallel.

b.

\section{MIMIC LINES}

(1) Differential line widths to code flow paths.

(2) No overlapping of mimic lines

(3) Flow direction indicated with arrowheads.

(4) Origin points are labeled.

(5) Terminal points are labeled.

(6) Component representations identified.

c. SYMBOLS
(1) Readily understood
(2) Consistent usage.

\section{PANEL LAYOUT}

6.8.1.1

Assigning Panel Contents

a. Grouping By Task Sequence

b. Grouping By System Function

c. Grouping By Importance And Frequency

\subsubsection{Effective Panel Contents}

6.8.1.3

Enhancing Recognition and Identification
a. Spacing
b. Demarcation
c. Color Shading
d. Emergency Controls 
6.8.2.1 Sequence, Frequency of Use, and Functional Considerations

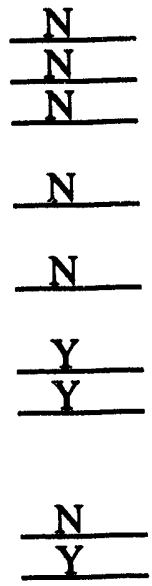

a. Sequence

(1) Specified Sequence

(2) Operated In Sequence

b. Frequency of Use

(3) Displays Symmetrical

(1) Located Near The Center of

(2) Preferred Visual \& Manual Areas

c. Functional Considerations

(1) Tasks Related To Specific Functions

(2) Identical In Purpose

6.8.2.2 Logical Arrangement and Layout

(a) Order and labeling

(b) Other expectations

\subsubsection{LAYOUT CONSISTENCY}

N/A (a) Repeated Functions

(b) Mirror- Imaging

\subsubsection{STANDARDIZATION}

$\frac{N}{N / A}$
(a) Panel to panel standardization
(b) Simulator-to-control room standardization

6.8 .3

SPECIFIC PANEL LAYOUT DESIGN

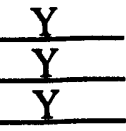

\subsubsection{1}

SEPARATION OF CONTROLS

(a) Access

(b) Inadvertent Actuation

(c) Simultaneous Actuation

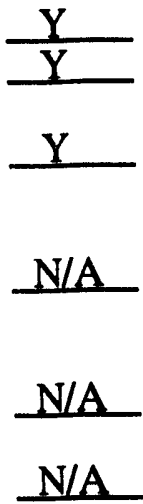

(a) Orientation

(b) String Length

(c) Number of Components

\section{STRINGS OR CLUSTERS OF SIMILAR} COMPONENTS

\subsubsection{MIRROR IMAGING}

6.9

$\begin{array}{ll}6.9 .1 & \text { BASIC CONTROL-DISPLAY } \\ \text { RELATIONSHIPS }\end{array}$


SINGLE CONTROL AND DISPLAY PAIRS

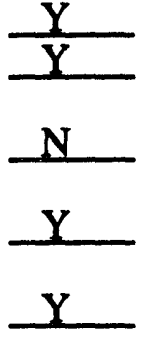

(a) Proximity

(b) Obscuration

(c) Association

(1) Association of displays with controls

(2) Direction of movement of controls and display

(3) The rate and limits of movement of the control \& display

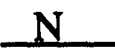

$N$

$\mathbf{N}$

$\mathbf{N}$
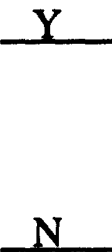

(6) Where the above techniques cannot apply, spacing demarcation, color shading, ect. should be employed

(b) SINGLE CONTROL, MULTIPLE DISPLAYS

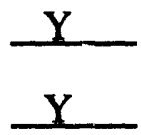

(1) Displays should be located above the control.

(2) The controls should be placed as near as possible to the display preferably underneath the display.

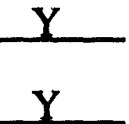

(3) Displays should be arranged horizontally or in a matrix.

(4) If it is not feasible to mount displays above the control, they should be mounted to the left of the control.

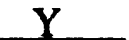

Where there is a normal order of use, displays should read from left-to-right, top-to-bottom, or in other natural sequence.

Where the above techniques cannot apply, or where for other reasons the control-display 


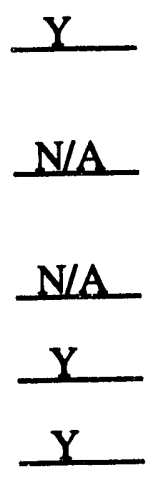

(c)

(7) Displays should not be obscured

relationship is not clearly apparent, layout enhancement techniques should be employed.

Display Selectors during control manipulation.

(1) The control should move clockwise from off (if appropriate) through settings $1,2,3 . . n$.

(2) The control position sequence should conform to the display sequence.

Control position indications should correspond with display labels.

Displays should read off-scale, not zero, when not selected, especially if zero is a possible parameter displayed.

\subsubsection{1}

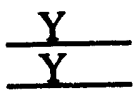

$\mathbf{N}$

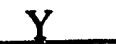

$\mathbf{N}$

$\mathrm{N}$

N/A

N/A

$\frac{N / A}{N / A}$

N/A

N/A

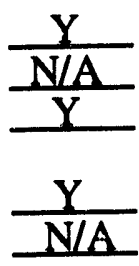

6.9.2.3

\section{LOCATION AND ARRANGEMENT OF CONTROL-DISPLAY GROUPS}

(a) Functional Integrity

(b) Sequence of Use

(a)

\section{SINGLE PANEL ARRANGEMENTS}

Display above each control

(1) Each display should be located directly above its associated control.

(2) The display/control pairs should be arranged in rows.

(b) Controls and Displays In Rows

(1) Each control should occupy the same relative position

(2) Controls and displays should have corresponding labels.

(c) Multi-Row Displays With Single-Row Controls

(1) Displays should be ordered left to right and top to bottom and matched to controls ordered left to right.

(2) Controls and displays should have corresponding labels.

(d) Consistent practice

(e) Control/display packages

CONTROLS AND DISPLAYS IN SEPARATE PLANES

(a) Separated controls and displays

$\begin{array}{ll}\text { 6.9.3.1 } & \text { GENERAL MOVEM } \\ \text { RELATIONSHIPS }\end{array}$

(b) Facing panels

(a) Rotary controls

(1) Linear scales, up or to the right

(2) Digital displays, increasing in value

(3) Circular meter pointers, clockwise.

(b)

Linear Controls

(1) Linear scales, up or the right.

(2) Digital displays, increasing in value. 
$\underline{Y}$

$Y$

N/A
(3) Strings of indicator lights, bottom-to-top or left-to-right.

(c) Display response time lag

(1) There should be no time lag between system condition change and display indication.

(2) When there is a time lag between control actuation and ultimate system state, there should be an immediate feedback indication of the process and change.

\subsubsection{2}

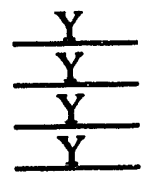

\section{CONTROL-DISPLAY RATIO}

(a) Controls

(b) Displays

(c) Excess precision

(d) Feedback

N/A - Guideline is not applicable

Y - Yes, complies with guideline

N - No, does not comply with guideline 

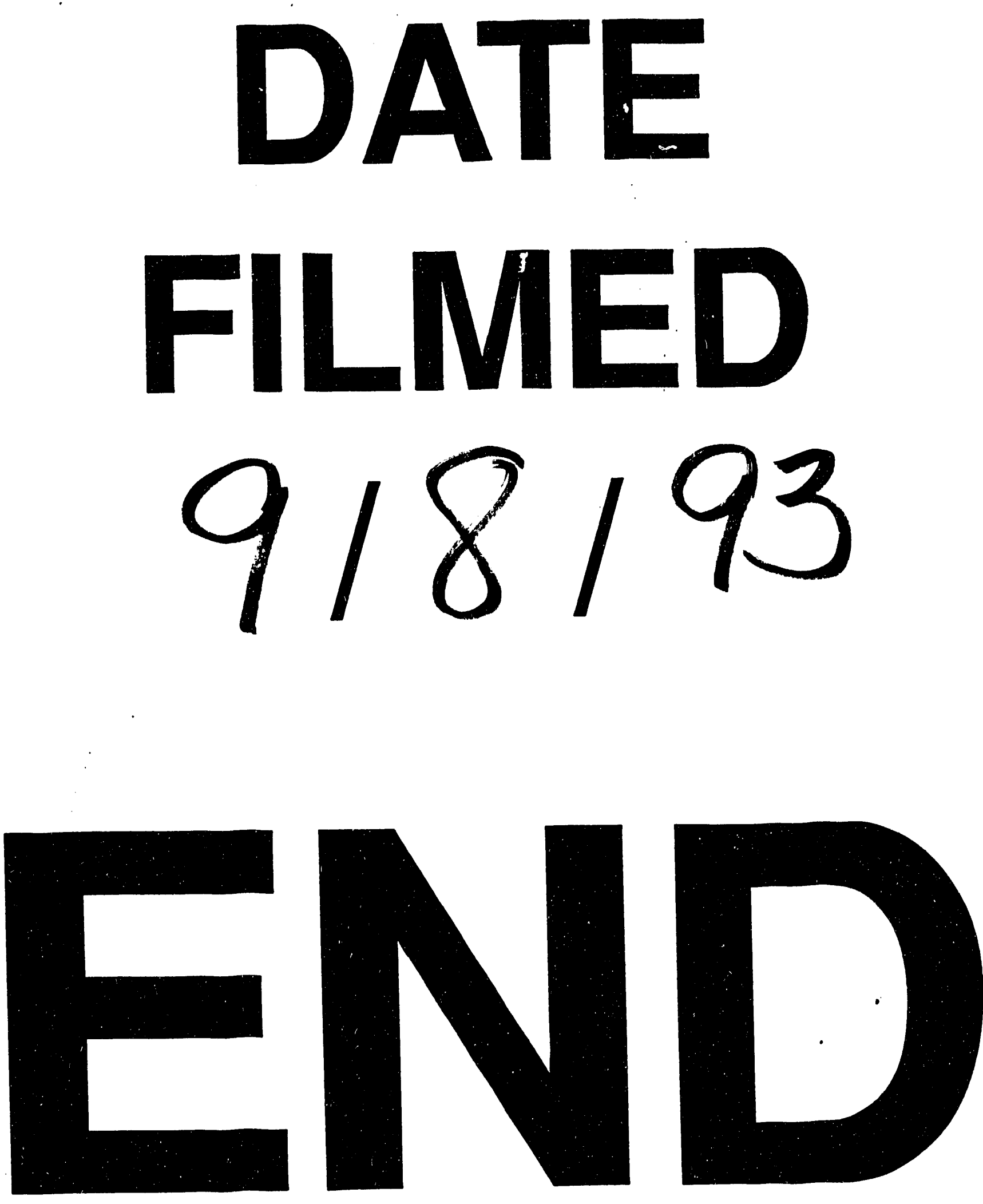
